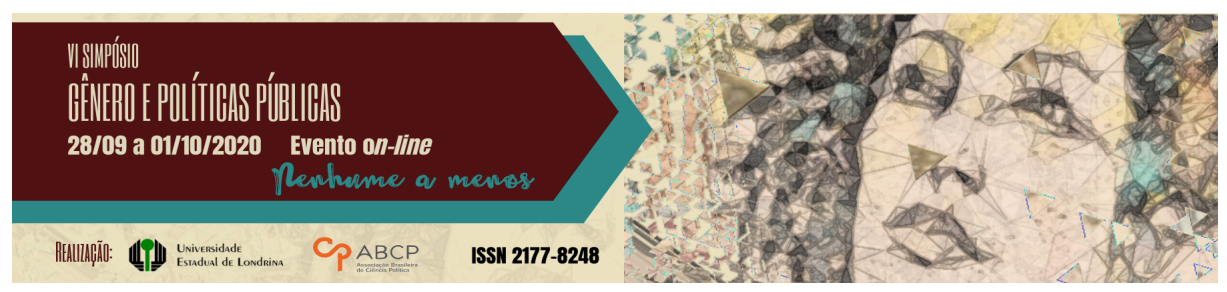

\title{
A construção da Política Pública Municipal para as Mulheres em Paiçandu/PR: desafios e perspectivas na efetivação da proteção social
}

\author{
Josivaldo Souza Reis'i; Karen Eduarda Alves Venâncio²; Beatriz Carla de Souza \\ Paludo ${ }^{3}$
}

\section{Resumo}

O presente artigo analisa e retrata os desafios e perspectivas do processo de construção, implementação, e efetivação da Política Pública Municipal para as Mulheres de Paiçandu/PR, mediante a construção de um robusto arcabouço jurídico normativo e de programas, serviços e ações atrelados à Secretaria Municipal de Assistência Social - SMAS, da Diretoria Municipal de Políticas para as Mulheres e da participação social das mulheres do município. Utilizase de pesquisa bibliográfica e documental com referência a realidade local, nacional e internacional e também análises das Pré-conferências Municipais de Políticas para as Mulheres, realizadas no município no ano de 2020. Conclui-se que a criação e implementação do Organismo Municipal de Políticas para as Mulheres no município tem se mostrado significativo para a efetivação dos direitos sociais das mulheres e que a participação social das mulheres na construção da Política Municipal, aponta desafios para a efetivação da proteção social neste segmento, sinalizando a necessidade de articulação de ações com a rede de atendimento às mulheres do município.

\footnotetext{
1 Secretário Municipal da Assistência Social de Paiçandu, Mestre em Ciências Sociais pela Universidade Estadual de Maringá (UEM), josivaldosreis@hotmail.com.

2 Psicóloga e Coordenadora da Diretoria Municipal da Política Pública para as Mulheres de Paiçandu-PR, Mestra em Psicologia pela Universidade Estadual de Maringá (UEM), karen.eav@hotmail.com.

${ }^{3}$ Psicóloga formada pela Uningá, foi Secretária Executiva do Conselho da Assistência Social e dos Conselhos de Direitos de Políticas Públicas em Paiçandu-PR até março de 2020, psicobeatriz.paludo@outlook.com.
}

GT 06 - Gênero, cuidado e políticas de saúde 
Palavras-chave: mulheres; políticas públicas; proteção

\title{
Paiçandu/PR's Municipal Public Policies for Women: challenges and perspectives in social protection effectuation
}

\begin{abstract}
This article discusses the challenges and perspectives of the construction, implementation and effectiveness of the Municipal Public Policy for Women in Paiçandu-PR. For this, bibliographical research and analysis of documents was carried out, with references to local, national and international reality. The discussions are also supported by analyzes of the social participation of women in the municipality, analyzes of normative legal documents and programs, services and actions linked to the Municipal Secretariat of Social Assistance - SMAS and to the Municipal Directorate of Policies for Women. It is concluded that the creation and implementation of the Municipal Policy Organization for Women in Paiçandu has been shown to be significant for the realization of women's social rights. Their participation in the construction of the Municipal Policy highlights challenges in the realization of social protection for this segment, signaling the need to articulate actions with the service network for women in the municipality.
\end{abstract}

Keywords: women; public policy; social protection.

\section{Introdução}

O estudo acerca do estado da arte aqui proposto possui como objetivo capilar a análise do processo de construção e efetivação da Política Pública Municipal para as Mulheres na cidade de Paiçandu/PR. Ademais, discute-se a proteção social para mulheres e a institucionalização desta política através do órgão gestor e, por fim, destaca o processo de participação das mulheres nas pré-conferências que antecedem a Conferência Municipal da Mulher e o exercício do Controle Social via Conselho Municipal dos Direitos da Mulher. 
Os Organismos Governamentais de Políticas para as Mulheres (OGPM) são responsáveis por articular, elaborar, sistematizar e implementar as políticas públicas para as mulheres nas instâncias municipal, estadual e federal. Tais órgãos são responsáveis pela gestão e articulação de ações em diferentes campos, como segurança, educação, assistência social, saúde, emprego, moradia, participação política, dentre outras.

Em 2013, no estado do Paraná, somente 12 dos 399 municípios possuíam Organismos Governamentais de Políticas para as Mulheres (OGPM), segundo o relatório final da Comissão Parlamentar Mista de Inquérito que investigou a situação das violências contra mulheres no território nacional (CAMPOS, 2015).

A partir disso, o presente estudo analisa, brevemente, o panorama que orbita essa temática, destacando o processo de construção, implementação, efetivação e fortalecimento da institucionalização da Política Pública Municipal para as Mulheres no município de Paiçandu/PR, através de ações da Secretaria Municipal de Assistência Social - SMAS, da Diretoria Municipal de Políticas para as Mulheres e da participação social das mulheres através das préconferências de políticas para as mulheres realizadas do município.

\section{Proteção social e o percurso da Política Pública Municipal para as Mulheres em Paiçandu}

Dissertar sobre o tema da proteção social, no âmbito da sociedade do capital, é uma tarefa hercúlea, antes de tudo, exige uma leitura crítica sobre o evolver das relações sociohistóricas haja vista que a formação da sociedade é marcada por relações dialéticas e contraditórias.

Segundo Sposati (2013): 
A proteção social, política pública de forte calibre humano, carrega marca genética que a torna um tanto distinta de outras políticas sociais. Seu campo de ação não se refere, propriamente, à provisão de condições de reprodução social para restauração da força viva de trabalho humano. As atenções que produz constituem respostas a necessidades de dependência, fragilidade, vitimização de demanda universal porque próprias da condição humana. (SPOSATI, 2013, p. 1).

Com as transformações operadas no âmbito das políticas públicas de proteção social, o poder público estatal busca interromper e reparar as desigualdades ocasionadas no âmbito do modo de produção capitalista, no qual, a questão de gênero é estrutural e sistêmica.

Cabe destacar que a Constituição Federal de 1988 cristaliza um processo iniciado nos idos das primeiras décadas do século XX quando da aprovação do Decreto Lei n. 4682/1923, denominado Lei Eloy Chaves em 1923. A partir de então passou-se a trilhar os rumos do que em 1988 tornou-se a tríade de um Sistema Brasileiro de Proteção Social (SBPS), relegando ao passado a cultura caudal paternalista, assistencialistas, focalistas, clientelistas, reducionistas e mecanicistas.

Portanto, a Constituição de 1988 ratifica e marca o ápice das reivindicações das camadas sociais da classe trabalhadora desenvolvida ao longo de todo o século $X X$ e que ganhou fôlego com a redemocratização política do País, de modo que conquistou um título específico para tratar da proteção social.

Destarte, as políticas sociais públicas passaram a ser redesenhadas sendo notórias a sua capilaridade na seara da política pública de seguridade social como um grande paralelo assistência social, saúde e previdência, isto é, o que antes esteve a cargo de diversas instituições, na maioria das vezes, em âmbito da filantropia privada, passou a ser dever do Estado, direito de todo cidadão, de modo que começou a ser inserida na agenda decisória governamental brasileira, 
produzindo uma profunda transformação na concepção de proteção social, nas suas condições de oferta, na sua organização institucional e na sua cobertura.

Não obstante toda correlação de forças e ventos contrários vindos dos "donos" do poder, muitos dos quais integram o legislativo brasileiro, e que prostram a luta da classe trabalhadora, a Constituição Federal de 1988 mantém-se resistente: "se mostrou primordial no longo processo, ainda em curso, de inscrição dos direitos sociais nos marcos institucional e legal do Estado brasileiro com reais consequências no papel governamental na garantia desses direitos por meio de políticas públicas" (SÁTYRO; SCHETTINI, 2011, p. 9).

Importa compreender a necessidade de sempre lançarmos mão as construções históricas da proteção social brasileira, para assim nos desvencilharmos das armadilhas do capital, pois, a proteção social é inegociável, e sua reprodução precisa acontecer a partir do Estado Democrático e de Direito, cujos limites são adstritos à esfera estatal pública.

De acordo com Jaccoud (2009):

a proteção social, no conceito aqui apresentado, se distingue da definição de políticas sociais, podendo ser entendida como parte delas. Fazem parte de um conjunto de iniciativas públicas com o objetivo de realizar fora da esfera privada o acesso a bens, serviços e renda. Seus objetivos são amplos e complexos, podendo organizar-se não apenas para a cobertura de riscos sociais, mas também para a equalização de oportunidades, o enfrentamento das situações de destituição e pobreza, o combate às desigualdades sociais e a melhoria das condições sociais da população (JACCOUD, 2009, p. 60).

Outrossim, é elementar reconhecer que a proteção social na Constituição Federal de 1988 não se limita a tríade da seguridade social, posto que aos tratar dos direitos fundamentais da constituição observa- 
se que eles transcendem a saúde, a previdência e a assistência social, ou seja, alcançam outros direitos, sobretudo aqueles inscritos no art. $5^{\circ}$ e art. $6^{\circ}$ da Constituição Federal de 1988, especificamente aquele previsto no inciso I do art. $5^{\circ}$ que aduz: "homens e mulheres são iguais em direitos e obrigações, nos termos desta Constituição".

Note-se que, o legislador buscou desde logo a igualdade de gênero, dessa forma, podemos perceber que a própria Constituição de 1988 proclamou o percurso para as políticas afirmativas de gênero e, para a ruptura da cultura patriarcal e das estruturas discriminatórias, sobretudo aquelas que subjugam o gênero feminino.

Segundo Pontes e Damasceno (2017), é possível observar que a Carta Magna aprovada em 1988 incorpora a maioria das reivindicações de movimento de mulheres, movimentos feministas e do Conselho Nacional de Direitos da Mulher (CNDM), criado através da Lei $n^{\circ}$ 27.353, assinada em 29 de agosto de 1985.

Como na Constituição de 1988 tais movimentos também impactaram de maneira fundamental os anos de 1980 e 1990 quando no debate sobre os direitos das mulheres, concentrada na questão de gênero, propuseram e articularam políticas públicas que instauraram mecanismos de visibilidade, autonomia, garantia de direitos e fortalecimento das mulheres nos espaços privados e públicos da sociedade brasileira.

Farah (2004) chama atenção quando enfatiza que a inclusão da questão de gênero na agenda governamental ocorreu como parte do processo de democratização, o qual significou a inclusão de novos atores no cenário político e, ao mesmo tempo, a incorporação de novos temas pela agenda política. Os movimentos sociais que participaram de lutas pela redemocratização do regime tinham as mulheres como um de seus integrantes fundamentais "a história desses movimentos é também a da constituição das mulheres como sujeito coletivo, em que estas deixam a 
esfera privada e passam a atuar no espaço público, tornando públicos temas até então confinados à esfera privada" (FARAH, 2004, p. 50).

Em 1996, o Brasil sanciona através do Decreto n. ${ }^{\circ}$ 1.973/1996 a Convenção Interamericana para Prevenir, Punir e Erradicar a Violência contra a Mulher, concluída em Belém do Pará, em 9 de junho de 1994, passando o Brasil a ser signatário. O artigo $5^{\circ}$ da Convenção aduz que:

Toda mulher poderá exercer livre e plenamente seus direitos civis, políticos, econômicos, sociais e culturais, e contará com a total proteção desses direitos consagrados nos instrumentos regionais e internacionais sobre direitos humano. Os Estados Partes reconhecem que a violência contra a mulher impede e anula o exercício desses direitos (BRASIL, 1996, s/p).

Pode-se dizer que, ao recepcionar esta convenção, o Brasil reafirma o compromisso com a defesa dos direitos humanos e de proteger o gênero feminino como detentora desses e de vários outros direitos.

Ainda no âmbito das convenções, em 2002, através do Decreto n. ${ }^{\circ}$ 4377/2002 o Brasil adere à Convenção sobre a Eliminação de todas as formas de discriminação contra a mulher, dando mais um passo importante no que tange à legislação.

Com a sanção destas convenções houve a edição de inúmeros mecanismos de proteção às mulheres, a Lei n. ${ }^{\circ}$ 11.340/2006 conhecida como "Lei Maria da Penha" é uma das mais consistentes e robustas Leis de proteção à mulher, em seu art. $2^{\circ}$ estabelece que:

Toda mulher, independentemente de classe, raça, etnia, orientação sexual, renda, cultura, nível educacional, idade e religião, goza dos direitos fundamentais inerentes à pessoa humana, sendo-lhe asseguradas as oportunidades e facilidades para viver sem violência, preservar sua saúde física e 
mental e seu aperfeiçoamento moral, intelectual e social (BRASIL, 2006, s/p).

Veja-se que, de modo germinal, a legislação se remete aos direitos fundamentais para afirmar a plenitude de direitos inerentes a todas as mulheres, tal como se encontra, também, na Convenção sancionada em 1996 acrescidos dos elementos da convenção sancionada em 2002.

Como observado, há vasto arcabouço jurídico normativo que visa a proteção social às mulheres. Na perspectiva da proteção social, em 1993, foi sancionada a Lei n. ${ }^{\circ}$ 8.742/1993 Lei Orgânica da Assistência Social (LOAS) que estabeleceu os pilares da proteção social não contributiva cujo objetivo é a proteção aos grupos socialmente vulneráveis, e, desse modo, abarcou o contingente de pessoas do gênero feminino, haja vista que, historicamente estiveram expostos e subjugados.

Na perspectiva da proteção, a LOAS em seu art. $2^{\circ}$ definiu como objetivos:

I. Proteção social, que visa à garantia da vida, à redução de danos e à prevenção da incidência de riscos [...]. III - a defesa de direitos, que visa a garantir o pleno acesso aos direitos no conjunto das provisões socioassistenciais (BRASIL, 1993, s/p).

Em vistas destes objetivos e pelo tradicional e histórico engajamento nas lutas em defesa das minorias, a defesa dos direitos das mulheres ganhou maior entonação na seara da Assistência Social.

Pontes e Damasceno (2017) afirmam que no ano de 2003, o então presidente Lula, instituiu o primeiro Organismo Governamental de Políticas para as Mulheres - (OGPM), a Secretaria de Políticas para as Mulheres (SPM), por meio da Lei $\mathrm{n}^{\mathrm{o}} 10.683$, de 28 de maio de 2003, fundada com o objetivo de erradicar todas as formas de desigualdade que atingem as mulheres, as quais ainda são partes constitutivas das populações ditas "vulneráveis". 
A partir da criação da SPM, as políticas de gênero em seus diversos campos (educacional, mercado de trabalho, econômico, de enfrentamento à todas as formas de violência contra as mulheres e conselhos) ganharam impulso.

No ano de 2018 foi instituído o Sistema Nacional de Políticas para as Mulheres e o Plano Nacional de Combate à Violência Doméstica criado através do Decreto n. ${ }^{\circ}$ 9586/2018, cujos objetivos eram:

Ampliar e fortalecer a formulação e a execução de políticas públicas de direitos das mulheres, de enfrentamento a todos os tipos de violência e da inclusão das mulheres nos processos de desenvolvimento social, econômico, político e cultural do País (BRASIL, 2018, s/p).

Atualmente, no Governo Federal, o Organismo Governamental de Políticas para as Mulheres continua sendo a Secretaria Nacional de Políticas para Mulheres (SNPM), vinculada ao Ministério da Mulher, Família e Direitos Humanos.

Cabe demarcar que, em que pese a Secretaria Nacional de Políticas para Mulheres (SNPM) ser um órgão cuja finalidade precípua seria a de encurtar e erradicar estruturas sociais marcadas pela estratificação de, e pelo gênero, em que homens e mulheres têm papéis previamente delimitados na sociedade, cujo mote "coisas de meninos versus coisas de meninas" e/ou "meninos vestem azul versus meninas vestem rosa" está na base da cultura do patriarcalismo e do patrimonialismo destinado a preservar a dominação e a reforçar as questões de gênero, este órgão tem negligenciado e/ou tem sido omisso quanto às temáticas consideradas polêmicas, colocando-se de forma conservadora frente às mesmas.

No Estado do Paraná o Organismo Estadual de Políticas para as Mulheres denomina-se de "Coordenação de Política para Mulheres", vinculado a Secretaria da Justiça, Família e Trabalho (SEJUF). 
Apesar de haver inúmeras legislações de promoção dos direitos às mulheres, considerando o Brasil enquanto um país de fronteiras intercontinental, é na seara da Assistência Social nos Municípios que vem ocorrendo a maioria das ações em defesa dos direitos das mulheres, uma vez que as estruturas administrativas municipais, ou seja, os serviços especializados e mecanismos de participação e controle social, em muitos municípios, dado o seu porte, não se configuram como Organismo Governamental de Políticas especificamente para as Mulheres.

Em geral, as equipes dos organismos municipais, coordenam estas ofertas de maneira articulada e integrada à rede de atendimento, potencializando as ações e as articulações entre os órgãos e poderes que atendem a diversidade e as múltiplas necessidades da população do gênero feminino.

$\mathrm{Na}$ perspectiva de estabelecer o atendimento às mulheres enquanto Política Pública em Paiçandu, em que pese já haver o comprometo e o engajamento do poder público municipal com a temática e ações de proteção social e promoção dos direitos das mulheres, várias legislações inovaram na perspectiva da proteção via políticas sociais públicas para mulheres no município.

Através da Lei Municipal n. ${ }^{\circ}$ 2.583/2017 foi instituída a semana municipal de combate à violência contra a mulher, a ser realizada na última semana do mês de novembro de cada ano, de acordo com esta Lei, são objetivos:

I. Conscientizar a população sobre as diferentes formas e graus de gravidade da violência contra à mulher. II. Divulgar e debater a Lei n. ${ }^{\circ} 11.340 / 2006$, conhecida como Lei Maria da Penha, e os instrumentos de proteção aos direitos humanos das mulheres. III. Promover e realizar campanhas educativas de prevenção da violência contra a mulher. IV. Fortalecer os mecanismos de combate à violência contra à mulher. V. Estimular o registro nos 
órgãos competentes das denúncias de violência contra à mulher (PAIÇANDU, 2017, s/p).

Percebe-se que a legislação pretérita traz à baila a questão da sensibilização da sociedade paiçanduense para a questão da violência contra a mulher no município. Outrossim, tem que se destacar a relevância da temática a ser tratada especificamente ao longo de toda uma semana pelos órgãos públicos municipais, inserindo dessa forma, a temática da prevenção e combate à violência contra à mulher na agenda do governo municipal e mais - no contexto da sociedade paiçanduense.

Ainda na seara da atenção, cuidado e promoção dos direitos das mulheres foi sancionada a Lei n. ${ }^{0}$ 2629/2018 a qual objetiva destacar e valorizar as mulheres que se destacam no município, além de prevê a realização de ações com a temática da defesa e proteção da mulher, a serem realizadas na segunda semana do mês de março coincidindo com a celebração do dia das mulheres, ou seja, configura-se em mais uma estratégia de trazer a temática de gênero à luz do dia.

Conforme apresentado e discutido acima, a temática da questão de gênero e nela dissolvida os direitos das mulheres no município de Paiçandu, ganhou especial atenção em meados da segunda década do século XXI, especificamente após o ano de 2017, em que, pode-se dizer que, do ponto de vista da legislação, inaugura-se o percurso para a solidificação de um política pública de grande envergadura a ser consolidada nos anos seguintes.

No ínterim de 8 (oito) anos a gestão municipal de Paiçandu, que se inicia em 2013 com a vitória do candidato do Partido dos Trabalhadores (PT), mostrou-se atenta aos acontecimentos no evolver das mudanças societárias no mundo, no Brasil e em Paiçandu, sobretudo, quanto à questão de gênero, promoção dos direitos das mulheres, prevenção e combate à violência contra às mulheres. 
Nesta direção foi sancionada a Lei Municipal n. ${ }^{\circ}$ 2.883/2019 exarada como os pilares de uma Política Pública Municipal para às mulheres, cujo poder público municipal é o seu provedor e financiador central, e destina-se a:

Art. $1^{\circ}$ provê mecanismos de acesso ao Sistema Brasileiro de Proteção Social e de Direitos, realizado através de um conjunto integrado de ações de iniciativa pública e da sociedade, com vistas ao pleno desenvolvimento da mulher no contexto da sociedade Paiçanduense (PAIÇANDU, 2019, s/p).

O foco desta Lei, de fato, é a estruturação de uma política pública para as mulheres na perspectiva de resguardar a dignidade da pessoa humana, haja vista que a mulher é detentora de direitos humanos irrenunciáveis a serem garantidos pelo poder público estatal, representado pelo município de Paiçandu, através dos objetivos insculpidos no $\operatorname{art} 5^{\circ}$ :

A Política Pública Municipal para as Mulheres tem como objetivos: I - A implantação e implementação de ações que visem a promoção dos direitos da mulher através de uma política pública global, visando eliminar todas as formas de discriminação que atinjam o gênero feminino, possibilitando sua integração e promoção como cidadã no aspecto econômico, social, político, educacional, cultural, dentre outros. II - A defesa de direitos garantindo o pleno acesso aos direitos no conjunto das provisões socioassistenciais. III- A implementação gradual e constante de políticas públicas afirmativas capazes de ampliar o exercício da cidadania das mulheres, necessariamente aqueles direitos que se destinam a efetivação de valores individuais, coletivos e sociais emancipatórios. IV - Romper valores estratificados, estereotipados, sexistas e preconceituosos em relação à ideologia dominante do patriarcalismo com vistas a superar a cultura da subalternidade social e política das mulheres. V - Promoção e inclusão da mulher ao mundo do trabalho. VI - A promoção e a inclusão da 
mulher na agenda política do Município. VII Prevenir e erradicar todas as formas de violência contra a mulher, aqui entendida como qualquer ato ou conduta baseada no gênero, que cause morte, dano ou sofrimento físico, sexual ou psicológico à mulher, tanto na esfera da vida pública como na esfera da vida privada. VIII - modificar os padrões sociais e culturais de conduta de homens e mulheres, inclusive a formulação de programas formais e não formais adequados a todos os níveis do processo educacional. IX - Combater preconceitos e costumes e todas as outras práticas baseadas na premissa da inferioridade ou superioridade de qualquer dos gêneros ou nos papéis estereotipados para o homem e a mulher, que legitimem ou exacerbam a violência contra a mulher (PAIÇANDU, 2019, s/p grifos no original).

Ademais, na perspectiva da participação e do controle social, a referida Lei Municipal n. ${ }^{\circ}$ 2.883/2019, instituiu o Conselho Municipal de Políticas Públicas para as mulheres em que, o planejamento e a formulação das ações são cotejadas à participação democrática tanto de setores governamentais como da sociedade civil organizada e movimentos sociais, cujas finalidades são determinadas no art. 17:

O Conselho Municipal da Mulher tem por finalidade assegurar à mulher a participação e conhecimento de seus direitos como cidadã, nas questões de gênero deste Município, em harmonia com as diretrizes traçadas pelo governo Estadual e Federal, e atuar no controle social de políticas públicas de igualdade de gênero, assim como exercer orientação normativa e consultiva (PAIÇANDU, 2019, s/p).

Para mais, com a sanção da Lei n. ${ }^{\circ}$ 2.883/2019, institui-se também a Conferência Municipal dos Direitos da mulher com poderes deliberativos em que "suas deliberações relativas à política de atendimento à mulher serão incorporadas ao Planejamento Estratégico dos órgãos públicos encarregados de sua execução e a suas propostas orçamentárias” (PAIÇANDU, 2019, s/p). 
Destaca-se que é patente a importância da participação exercida através do controle social democrático, seja no conselho municipal de políticas paras as mulheres seja na Conferência Municipal, cuja sociedade civil organizada figura como polo ativo em relação ao gerenciamento da política pública para as mulheres em Paiçandu, uma vez que a sociedade civil expressa-se dialeticamente contrapondo-se às hegemonias da sociedade capitalista muitas vezes representadas pelo poder público estatal. Montaño e Duriguetto (2011) ao dissertarem sobre a sociedade civil afirmam que:

Essa esfera designaria o espaço em que se manifesta a organização e a representação dos interesses dos diferentes grupos sociais, da elaboração e/ou difusão de valores, cultura e ideologia. A sociedade civil em Gramsci é assim composta por uma rede de organizações (associações, sindicatos, partidos, movimentos sociais, organizações profissionais, atividades culturais, meios de comunicação, sistema educacional, parlamento, igrejas, etc.). É uma das esferas sociais em que as classes organizam e defendem seus interesses, em que se confrontam projetos societários, na qual as classes e suas frações lutam para conservar ou conquistar hegemônia (MONTAÑO; DURIGUETTO, 2011, p. 43).

Por fim, em 13 de janeiro de 2020 foi Instituída a Diretoria da Política Pública Municipal para as Mulheres, através do Decreto 11/2020, a qual é "competente pela execução da Política Pública Municipal para as Mulheres no Município de Paiçandu nos termos definidos pela Lei $\mathrm{n}^{\circ}$ 2.883/2019 do Município de Paiçandu" (PAIÇANDU, 2020, s/p).

A diretoria enquanto órgão gestor da Política Pública Municipal para as Mulheres representa um grande marco, pois dá um passo muito importante. Espera-se que as autoridades públicas municipais entendam a extrema importância de se criar a Secretaria Municipal que trate especificamente dessa temática tão importante e tão 
contemporânea no evolver da sociabilidade da sociedade paiçanduense.

A partir do exposto pode-se afirmar que, no município de Paiçandu, formou-se um Sistema Municipal de Proteção Social de grande envergadura para a defesa e promoção dos Direitos das Mulheres, realizado através de um conjunto integrado de ações de iniciativa pública e da sociedade, cuja centralidade visa preservar a dignidade humana, com vistas ao pleno desenvolvimento da mulher no contexto da sociedade Paiçanduense.

Participação social, empoderamento e emancipação das mulheres nas pré-conferências da política pública municipal para as mulheres em Paiçandu

As Conferências de Políticas Públicas para as Mulheres são espaços democráticos de debate, participação e deliberação acerca de ações que visam o enfrentamento às desigualdades de gênero no Brasil.

Nos últimos dezesseis anos foram realizadas quatro Conferências Nacionais de Políticas para as Mulheres, respectivamente em 2004, 2007, 2011 e 2016. Tais eventos foram fundamentais para a construção dos Planos Nacionais de Políticas para as Mulheres (PNPM), documentos que resultaram de amplos diálogos entre o governo e a sociedade civil e nortearam as ações realizadas pelo Estado nos últimos anos, contribuindo para que fossem sancionadas, por exemplo, a Lei 11.340/06, conhecida popularmente como Lei Maria da Penha e a Lei 13.104/15, que altera o Código Penal, prevendo o feminicídio como circunstância qualificadora do crime de homicídio.

No ano de 2020 seria realizada a V Conferência Nacional de Políticas para as Mulheres, convocada pelo Decreto Nacional $n^{\circ}$ 9.585, de 27 de novembro de 2018, com o objetivo de garantir, fortalecer e ampliar a formulação e a execução de políticas públicas de direitos das 
mulheres, com vistas ao enfrentamento a todas as formas de violência, bem como facilitar a participação, a inclusão, o trabalho, a autonomia social, econômica, política e cultural das mulheres no Brasil. O evento, segundo o artigo $3^{\circ}$ da Resolução $n^{\circ} 01$, de 05 de julho de 2019, do Conselho Nacional dos Direitos da Mulher, deveria ser precedido pelas conferências municipais ou intermunicipais, conferências estaduais e distritais e por conferências livres.

O município de Paiçandu, estado do Paraná, instituiu a Conferência Municipal de Políticas para as Mulheres através da Lei Municipal 2.883/19, convocando a I Conferência através do Edital n ${ }^{\circ} 01$, de 27 de janeiro de 2020, da Diretoria Municipal de Políticas para as Mulheres. O evento seria realizado em 17 de março de 2020, contudo, após o Decreto $n^{\circ} 4.230 / 2020$, do governo do Estado do Paraná, que determinava a suspensão de eventos com aglomeração acima de cinquenta pessoas, em virtude da pandemia da COVID-19, o evento foi adiado.

Cabe a observação de que o órgão gestor da Política Pública para as Mulheres ficou responsável pela convocação do evento, visto que o Conselho Municipal dos Direitos da Mulher, instituído também pela Lei Municipal 2.883/19, não havia ainda sido formado, uma vez que a eleição das conselheiras ocorreria durante o evento da I Conferência Municipal da Mulher.

Como forma de preparação da I Conferência Municipal da Mulher, foram realizadas as Pré-conferências Municipais de Políticas Públicas para as Mulheres de Paiçandu, eventos que antecederam a I Conferência, as quais foram fundamentais para a mobilização social, através de diálogos e debates sobre os desafios e conquistas no enfrentamento às desigualdades de gênero em diferentes territórios.

Ao todo, foram realizadas cinco pré-conferências, em diferentes locais do território do município de Paiçandu e Distrito de Água Boa: Bela Vista I (Centro de Convivência do Idoso), Centro (Centro de 
Referência de Assistência Social/CRAS), Parque São Jorge, Jardim Santa Efigênia (Colégio Estadual Vercindes Gerotto dos Reis) e Distrito de Água Boa (Centro).

Participaram das cinco pré-conferências 181 pessoas da sociedade civil e trabalhadoras/es que atuam no poder público executivo municipal. Foram elaboradas 97 propostas, dividas em três eixos, de acordo com a orientação do Conselho Nacional dos Direitos da Mulher (CNDM): I) A Política Nacional para as Mulheres: avanços e desafios e o papel do Estado na gestão das políticas para as mulheres; II) O Sistema Nacional de Políticas para as Mulheres: propostas de Estrutura, inter-relações, instrumentos de gestão, recursos, políticas nacional de formação, estratégias de institucionalização regulamentação e implementação do Sistema; III) Políticas Públicas Temáticas para as Mulheres: avanços e desafios e enfrentamento às violências, saúde integral, trabalho, autonomia economia, participação nos espaços de poder e decisão educação para a igualdade e diversidade.

As propostas mais frequentes ao longo das cinco préconferências foram: ações para garantia de autonomia financeira, como, por exemplo, cursos profissionalizantes e capacitações profissionais; criação de Delegacia Especializada no Atendimento à Mulher (DEAM); ampliação de vagas em creches; ações que visem a garantia da saúde integral das mulheres; necessidade de capacitação da rede de atendimento e/ou enfrentamento às violências; realização de eventos e encontros que debatam temas relativos às vivências das mulheres e contribuam para o exercício da cidadania e participação das mulheres nos espaços públicos de decisão.

Destaca-se também algumas propostas específicas de alguns territórios, como, por exemplo, as sugestões de melhorias na iluminação pública, no transporte coletivo e pavimentação de ruas na conferência realizada no Parque São Jorge e a criação de cooperativas de artesanato, vestuário e agricultura para mulheres na pré-conferência realizada no 
distrito de Água Boa. Estas demandas em específico foram apontadas como meio de prevenir a ocorrência de violências, como roubos, agressão física, dentre outras.

As similaridades e diferenças entre as propostas das préconferências sinalizam que diversas usuárias identificam demandas parecidas, contudo observa-se também singularidades em alguns territórios do município de Paiçandu e distrito de Água Boa.

A territorialização do processo, ou seja, a realização das etapas em diferentes bairros do município e distrito, possibilitou a representação social de mulheres de diferentes localidades, faixas etárias, classes sociais, orientações sexuais, identidades de gênero, raça/etnia.

A pré-conferência realizada no bairro Bela Vista I, no Centro de Convivência do Idoso, por exemplo, contou com a participação majoritária de mulheres idosas (com 60 anos ou mais), em contrapartida, a pré-conferência realizada no Jardim Santa Efigênia, no Colégio Estadual Vercindes Gerotto dos Reis, teve a participação de adolescentes, homens e mulheres, com idade entre 16 e 18 anos.

A participação social é fundamental no processo de construção e implementação de políticas públicas, pois trata-se de diretrizes e princípios que norteiam as ações do poder público, mas que devem ser construídas democraticamente pela sociedade e o Estado.

Nas sociedades democráticas, a participação política, segundo Moroni (2009), não se limita às modalidades em que tradicionalmente é associada, que é, o direito de votar e/ou ser votado. Segundo o autor, é necessário criar novas modalidades de participação política, ou seja, outras possibilidades de exercício do direito fundamental do ser humano de participar ativamente das decisões do seu país, assim como preconiza o artigo XXI da Declaração Universal dos Direitos Humanos. 
A participação política em modalidades fora das tradicionais, como as destacadas por Moroni (2009), não é comumente praticada. No Brasil, relaciona-se também com as instabilidades políticas ao longo da história do país como República, em que somente cinco presidentes eleitos democraticamente conseguiram terminar o mandato nos últimos noventa anos.

Quando analisamos pelo viés de gênero a participação política é ainda mais restrita, visto que em uma sociedade estruturalmente machista, a presença das mulheres nos espaços públicos de decisão é ainda menor. Tendo em consideração tais discussões, a participação das mulheres nas Conferências e Conselhos de Direito, ocupando espaços de poder e decisão, mostra-se uma possibilidade de participação política democrática, capaz de criar fissuras em estruturas que sustentam e produzem desigualdades.

O impacto da participação social das mulheres nos processos de decisão, segundo Brasil e Reis (2015) afeta diretamente o direcionamento das políticas públicas, contribuindo para a ampliação e aprofundamento da democracia. As autoras destacam também o importante papel da sociedade civil organizada e do ativismo político plural, que pode ocorrer através de movimentos sociais, redes articuladoras, sindicatos, entre outros.

As pré-conferências mostraram-se também espaços significativos para a ampliação do conhecimento das mulheres sobre a rede de atendimento e enfrentamento e também de legislações que visam à proteção e o enfrentamento às violências. De acordo com a pesquisa realizada por Brasil e Reis (2015) a partir das experiências das Conferências Municipais de Políticas para as Mulheres realizadas no município de Belo Horizonte/MG, diversas conselheiras também apontaram que os eventos foram espaços de caráter educativo relevantes. 
As experiências das prés-conferências no município de Paiçandu e distrito de Água Boa, mostraram que o encontro entre diferentes mulheres proporciona o debate e o compartilhamento de experiências, fazendo com que muitas identifiquem semelhanças e diferenças em suas trajetórias de vida e nas relações afetivas que já estabeleceram. Brasil e Reis (2015) apontam que as conferências possibilitam que as mulheres se atentam às suas realidades, principalmente no encontro com outras mulheres. Dentro dessa perspectiva, a participação social não um processo somente individual, mas também coletivo, tornando-se um importante instrumento de transformação subjetiva e comunitária.

Para se efetivarem as propostas aprovadas nas conferências realizadas nos três níveis de governo são necessários planejamentos dos Organismos Governamentais de Políticas para Mulheres (OPM) e também o acompanhamento contínuo das ações, através por exemplo, do controle social exercido pelos Conselho dos Direitos da Mulher.

A partir das experiências das pré-conferências foi possível identificar que as mulheres, ao se informarem sobre seus direitos e serviços ofertados pela rede de atendimento e enfrentamento no município, podem exercer o controle social e acompanhamento das ações desenvolvidas no município.

A pesquisa realizada por Brasil e Reis (2015) mostrou que existem dificuldades na articulação e gestão das propostas aprovadas em Conferências de Políticas para as Mulheres. Após identificadas as necessidades e aprovadas as propostas, passamos para uma próxima etapa que é permeada de desafios: como fazer?

A resposta para o questionamento anterior trás constantes inquietações às/aos gestoras/es municipais. As experiências do processo de construção, implementação, efetivação e o fortalecimento da institucionalização da Política Pública Municipal para as Mulheres de Paiçandu/PR, assim como o processo de realização das préconferências, mostraram que os guias orientativos e normativos 
elaborados ao longo dos últimos anos pela Secretaria Nacional de Políticas para as Mulheres são importantes diretrizes.

Contudo não devem ser compreendidos como fórmulas prontas para a execução de políticas públicas para as mulheres, uma vez que deve-se orientar-se de acordo com as realidades locais e necessidades das mulheres do município.

Por fim, destaca-se que as pré-conferências mostraram-se basilares no diagnóstico necessário para a construção do Plano Municipal de Políticas para as Mulheres, documento que encontra-se em construção com o objetivo de fundamentar, regulamentar e orientar a execução das políticas públicas para as mulheres nos próximos anos.

\section{Conclusões}

As conclusões do presente estudo indicam apenas uma condição momentânea posto que não é nossa pretensão dar por esgotado a temática, distante disso, sabemos que o percurso ainda está apenas iniciado. Sobretudo se considerarmos que as últimas décadas têm sido marcadas pela correlação de forças dos movimentos de mulheres pelo reconhecimento da legitimidade das suas lutas e que tem no horizonte a busca pela equidade dos seus direitos.

Outrossim, deve-se reconhecer que no ínterim de mais de 3 (três) décadas desde a Constituição Federal de 1988, o Estado Brasileiro através do legislador empreendeu esforços na aprovação de legislações modernas relativas à temática de gênero, a saber: Convenções, Legislação penal, Conselhos e Conferências de direitos, órgãos específicos que direcionam as discussões sobre a questão de gênero, dentre outros.

O Estudo nos revelou também que, em 2002, o Brasil ratificou a Convenção para Eliminar Todas as Formas de Discriminação Contra as Mulheres, ampliando ainda mais o rol de legislação na proteção às 
mulheres, reafirmando seu posicionamento na prioridade de ações de proteção na seara política, econômica, social, cultural e civil, dentre outros (BRASIL, 2002).

Vimos que recentemente, o Decreto n. ${ }^{\circ}$ 9.586/2018 aprovou o Sistema Nacional de Políticas para as Mulheres e o Plano Nacional de Combate à Violência Doméstica. Esse conjunto de normas tornou robusto o sistema de proteção social, do ponto de vista normativo, no entanto, sua efetivação surge como desafio à luz da dialética do cotidiano que requer diversas mediações.

À luz da na legislação nacional, o município de Paiçandu deu passos importantes na perspectiva da promoção e proteção dos direitos das mulheres. Não obstante as campanhas realizadas anualmente pela Secretaria da Assistência Social, fez entender a necessidade de ampliar as ações acerca da intervenção do poder público.

Nessa perspectiva o executivo municipal empreendeu esforços na elaboração da Política Pública municipal para as Mulheres o Conselho da Mulher, a Conferência da mulher, o Fundo e o Plano Municipal, tratando a temática na seara da política pública.

Como resultados principais, o trabalho indicou a importância da participação social das mulheres na construção da Política Municipal, apontou desafios para a efetivação da proteção social neste segmento e sinalizou a necessidade de articulação de ações com a rede de atendimento às mulheres do município.

Como dito preteritamente, os resultados trazidos à baila são apontamentos preliminares de uma política pública inacabada e em construção porém, sinaliza sua grande potencialidade e sua preciosidade e como um grande diamante precisa ser lapidada mediante os calorosos debates da sociedade Paiçanduense, tendo sempre à frente a busca pela emancipação de todas as mulheres. 


\section{Referências}

BRASIL Presidência da República. Decreto $n^{\circ} 4.377$, de 13 de setembro de 2002. Poder Executivo, Brasília, DF. Disponível em: http://www.planalto.gov.br/ccivil_03/decreto/2002/D4377.htm. Acesso em: 31 ago. 2020.

BRASIL, Flávia de Paula Duque; REIS, Girlene Galgani. Democracia, participação e inclusão política: um estudo sobre as conferências de políticas para as mulheres de Belo Horizonte. Revista do Serviço Público, v. 66, n. 1, p. 7-27, 2015.

BRASIL, Presidência da República. Constituição Federal de 1988. Brasília, DF. Disponível em: http:// www.planalto.gov.br/ccivil_03/constituicao/constituicao.ht m. Acesso em: 31 ago. 2020.

BRASIL. Presidência da República. Decreto Lei $n^{\circ} 4682$ de 24 de janeiro de 1923. Poder Executivo, Brasília, DF. Disponível em: http:// www.planalto.gov.br/ccivil_03/decreto/historicos/dpl/DPL 4682-1923.htm. Acesso em: 31 ago. 2020.

BRASIL. Presidência da República. Decreto no 1.973, de 1 de agosto de 1996. Poder Executivo, Brasília, DF. Disponível em: http://www.planalto.gov.br/ccivil_03/decreto/1996/D1973.htm\#: :text=DECRETO $\% 20 \mathrm{~N} \%$ C2\%BA \% 201.973\%2C\%20DE\% 201\%C2\%BA, 9\%20de\%20junho\%20de\%201994. Acesso em: 31 ago. 2020.

BRASIL. Presidência da República. Decreto $n^{\circ}$ 9.586, de 27 de novembro de 2018. Poder Executivo, Brasília, DF. Disponível em: http://www.planalto.gov.br/ccivil_03/_ato20152018/2018/decreto/D9586.htm. Acesso em: 31 ago. 2020.

BRASIL. Presidência da República. Lei n. ${ }^{\circ} 11.340$ de 7 de agosto de 2006. Disponível em: http://www.planalto.gov.br/ccivil_03/_ato20042006/2006/lei/111340.htm. Acesso em: 29 ago. 2020.

BRASIL. Presidência da República. Lei no 8742 de 7 de dezembro de 1993. Poder Executivo, Brasília, DF. Disponível em: 
http://www.planalto.gov.br/ccivil_03/leis/18742.htm. Acesso em: 31 ago. 2020.

CAMPOS, Carmen Hein de. A CPMI da violência contra a mulher e a implementação da Lei Maria da Penha. Estudos Feministas, v. 23, n. 2, p. 519-531, 2015.

FARAH, Marta Ferreira Santos. Gênero e Políticas Públicas. Escola de Administração de Empresas de São Paulo da Fundação Getulio Vargas. Estudos Feministas, Florianópolis, 2004.

JACCOUD, Luciana. Proteção Social no Brasil: debates e desafios. In: MDS. Concepção e gestão da proteção social não contributiva no Brasil. Brasília: MDS/Unesco, 2009. p. 57-86.

MONTANO, Carlos.; DURIGUETTO, Maria Lúcia. Estado, Classe e Movimento Social. 2. ed. São Paulo: Cortez, 2011.

MORONI, José Antônio. O direito à participação no governo Lula. Saúde em debate, v. 29, n. 71, p. 284-304, 2005.

PAIÇANDU. Prefeitura Municipal. Decreto Municipal $n^{0} 11$, de 13 de janeiro de 2020. Disponível em: http:/ / www.controlemunicipal.com.br/site/diario/publicacao.php? $\mathrm{id}=143396 \&$ \&d_cliente=17. Acesso em: 31 ago. 2020.

PAIÇANDU. Prefeitura Municipal. Lei Municipal $n^{\circ} 2.583$ de 10 de novembro de 2017. Diário Oficial de Paiçandu, Poder Executivo, Paiçandu, PR. Disponível em: http:/ / www.ingadigital.com.br/transparencia/?id_cliente=17\&sess ao=b054603368d1b0. Acesso em: 31 ago. 2020.

PAIÇANDU. Prefeitura Municipal. Lei Municipal no 2.629 de 20 de dezembro de 2019. Diário Oficial de Paiçandu, Poder Executivo, Paiçandu, PR, 08 jan. 2020. Disponível: http:/ / www.ingadigital.com.br/transparencia/?id_cliente=17\&sess ao=b054603368d1b0. Acesso em: 31 ago. 2020.

PAIÇANDU. Prefeitura Municipal. Lei Municipal $n^{0}$ 2.883, de 20 de dezembro de 2019. Diário Oficial de Paiçandu, Poder Executivo, Paiçandu, PR, 08 jan. 2020. Disponível em: 
http:/ / www.ingadigital.com.br/transparencia/?id_cliente=17\&sess $\mathrm{ao}=\mathrm{b} 05460368 \mathrm{~d} 1 \mathrm{~b} 0$. Acesso em: 31 ago. 2020.

PONTES, Denyse; DAMASCENO, Patrícia. As Políticas para as mulheres no Brasil: avanços, conquistas e desafios contemporâneos. Seminário Internacional Fazendo Gênero, v. 11, p. 1-11, 2017.

SÁTYRO, Natália Guimarães Duarte; SCHETTINI. Eleonora Martins Cunha. A entrada da Política de Assistência Social na agenda decisória brasileira:o papel das leis e o papel do presidente. $35^{\circ}$ Encontro Anual da ANPOCS, p. 1-27, 2011.

SPOSATI, Aldaíza. Proteção social e seguridade social no Brasil: pautas para o trabalho do assistente social. Serv. Soc. Soc., São Paulo, n. 116, p. 652-674, out./dez. 2013. 